\title{
Properties of Prussian Blue Materials Manifested in Molecular Complexes: Observation of Cyanide Linkage Isomerism and Spin-Crossover Behavior in Pentanuclear Cyanide Clusters
}

Mikhail Shatruk, ${ }^{\dagger}$ Alina Dragulescu-Andrasi, ${ }^{\dagger}$ Kristen Chambers, ${ }^{\dagger}$ Sebastian A. Stoian,${ }^{\ddagger}$ Emile L. Bominaar, ${ }^{\ddagger}$ Catalina Achim, ${ }^{*},{ }^{\star}$ Kim R. Dunbar* ${ }^{\dagger}$

Department of Chemistry, Texas A\&M University, College Station, Texas 77842-3012, Department of Chemistry, Carnegie Mellon University, 4400 Fifth Avenue, Pittsburgh, Pennsylvania 15213

\section{Supporting Information}

Figure S1. Weight loss observed for compounds $1-5$ in the temperature range of $25-300^{\circ} \mathrm{C} \ldots . .2$

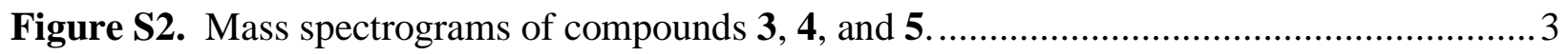

Figure S3. Mössbauer spectrum of 2 at $50 \mathrm{~K}$ in an applied field of $0.05 \mathrm{~T}$............................ 4

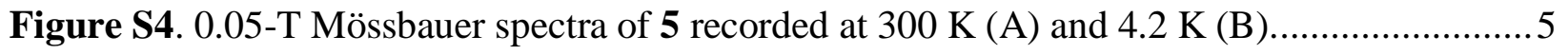

Figure S5. Mössbauer spectra of acetonitrile-wet crystals of 3........................................ 6

Figure S6. 4.2-K Mössbauer spectra of water-containing crystals of 4 (A) and 3 (B) recorded in

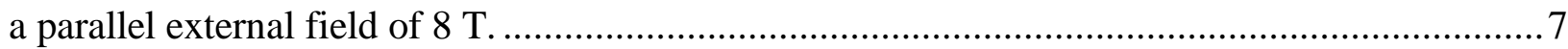

Figure S7. X-ray powder diffraction pattern for compound 4 ......................................... 8

Figure S8. 0.05 -T Mössbauer spectra recorded at 4.2 (A), and $220 \mathrm{~K}$ (B) for acetonitrile-wet

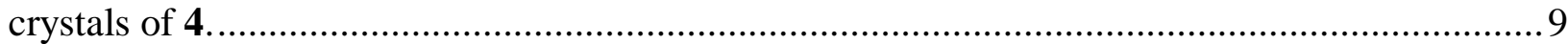

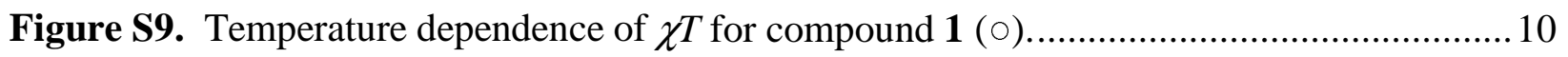

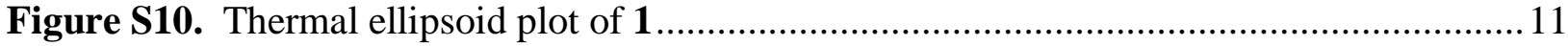

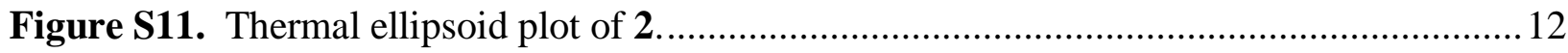

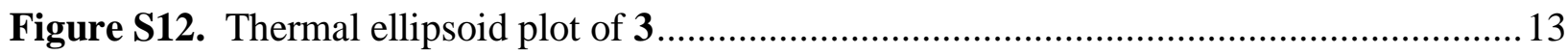

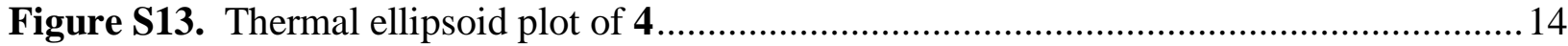

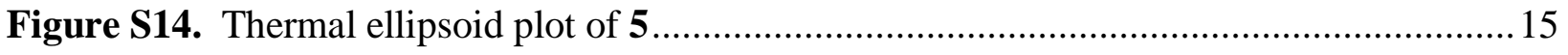




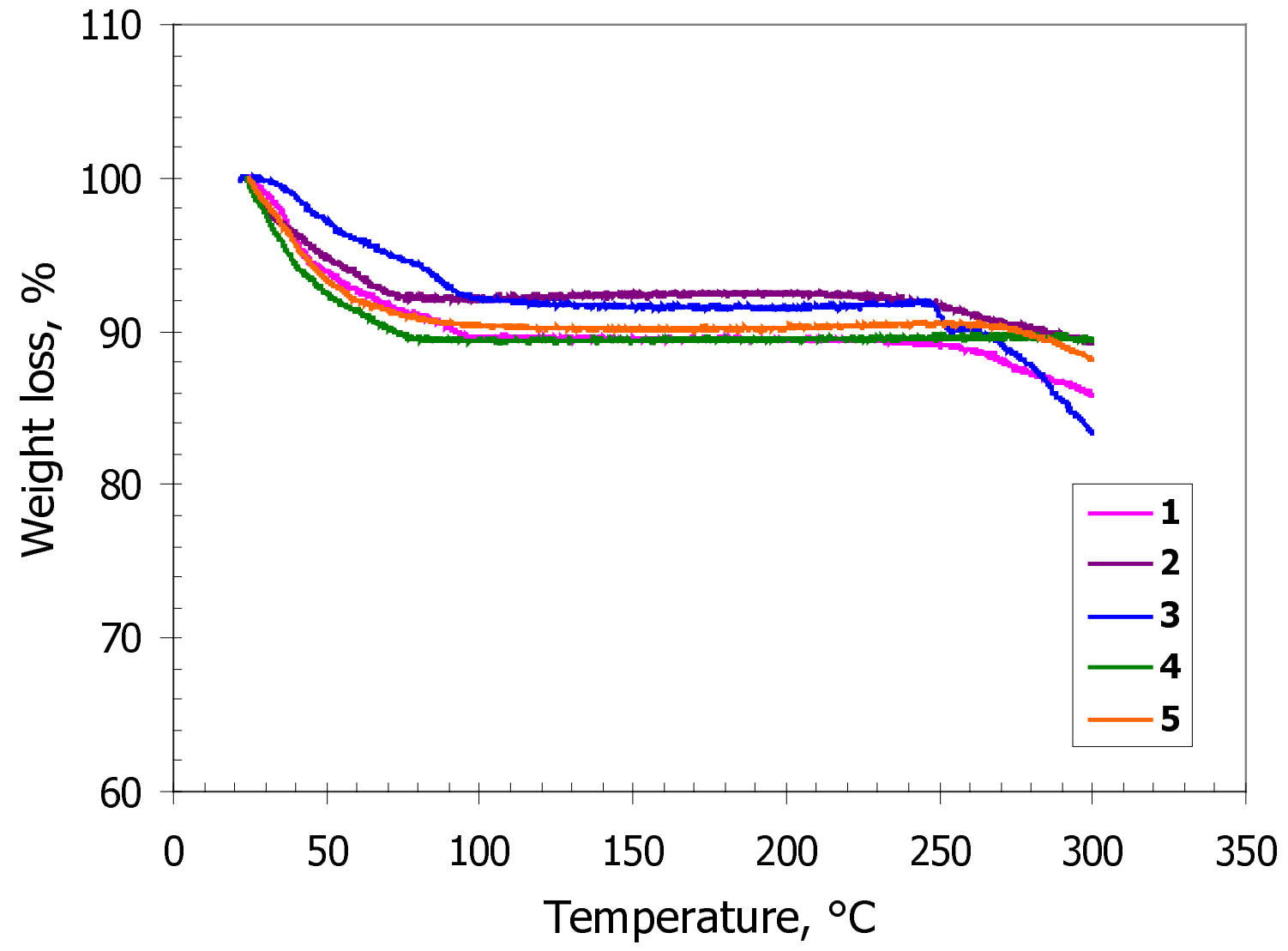

Figure S1. Weight loss observed for compounds $\mathbf{1 - 5}$ in the temperature range of $25-300^{\circ} \mathrm{C}$. 

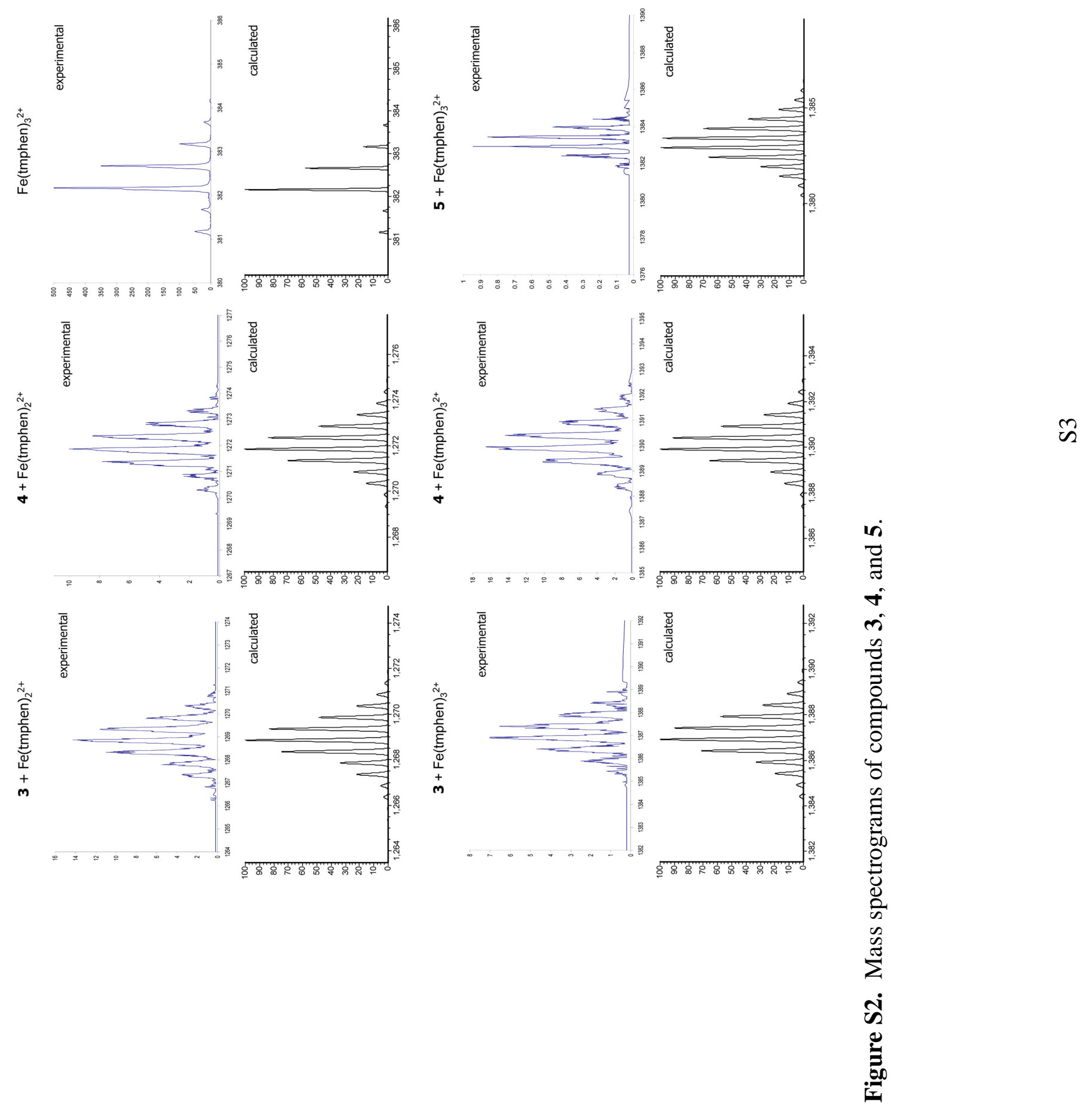


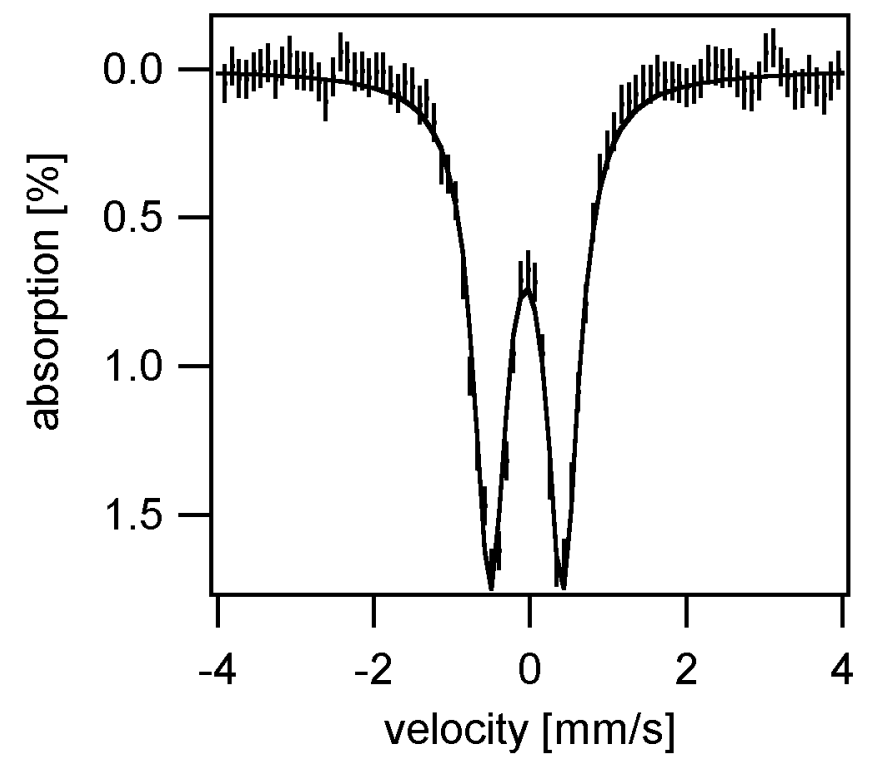

Figure S3. Mössbauer spectrum of 2 at $50 \mathrm{~K}$ in an applied field of $0.05 \mathrm{~T}$. 


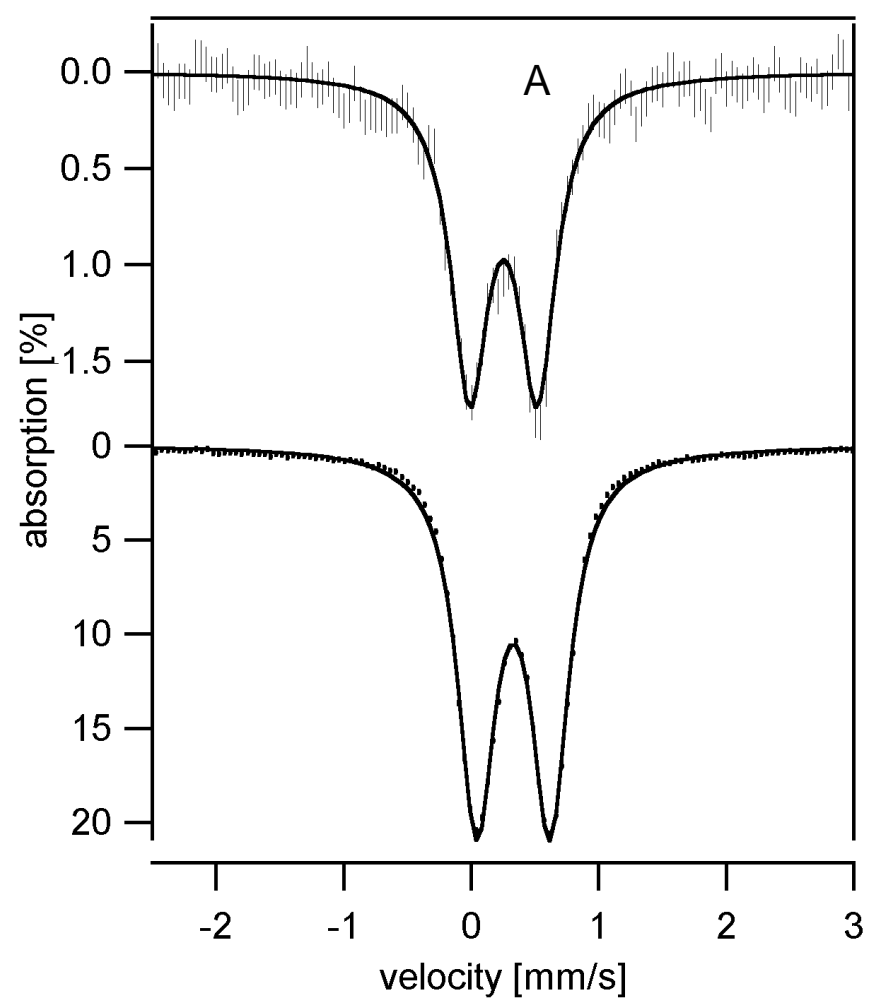

Figure S4. 0.05-T Mössbauer spectra of 5 recorded at $300 \mathrm{~K}$ (A) and 4.2 K (B).

Continuous lines drawn through the data represent simulations using quadrupole doublets with the parameters given in Table 2. 


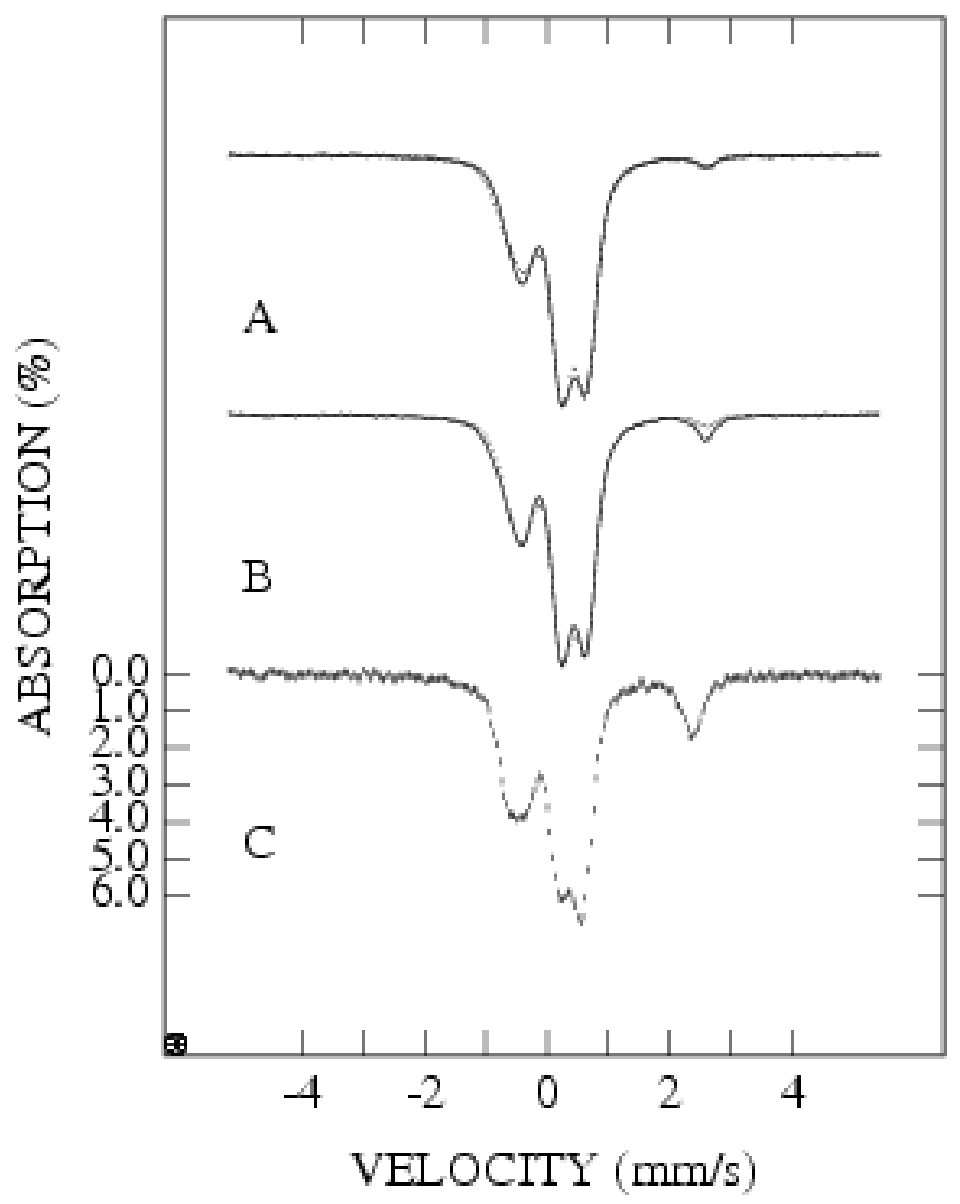

Figure S5. Mössbauer spectra of acetonitrile-wet crystals of $\mathbf{3}$.

(A) Comparison of $4.2 \mathrm{~K}$ (velocity bars) and $50 \mathrm{~K}$ (continous line) spectra; (B) Comparison of 50-K (velocity bars) and $100 \mathrm{~K}$ (continous line) spectra; Spectrum collected at $220 \mathrm{~K}$ (C). 


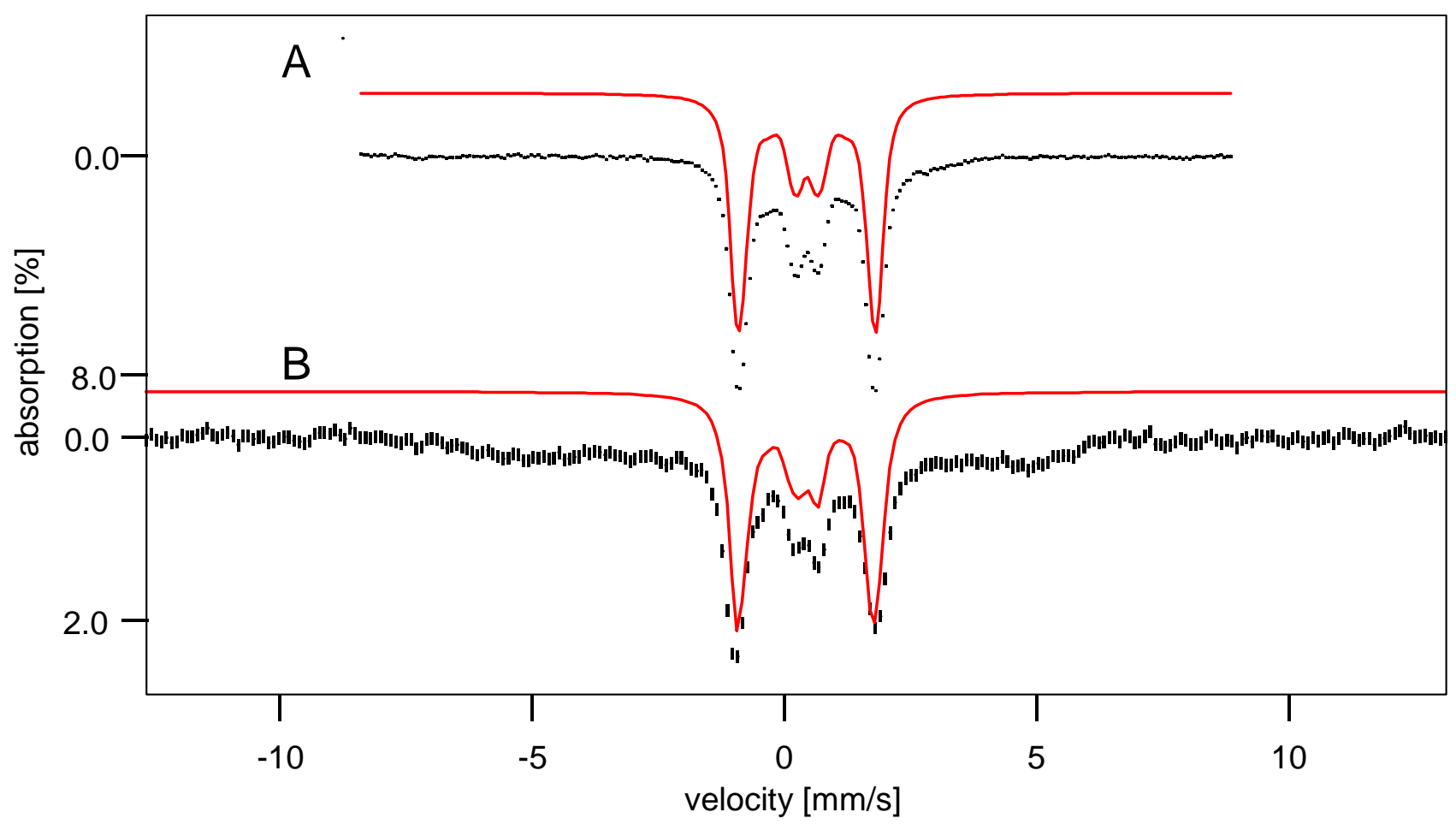

Figure S6. 4.2-K Mössbauer spectra of water-containing crystals of 4 (A) and 3 (B) recorded in a parallel external field of $8 \mathrm{~T}$.

The continuous lines shown in red are simulations assuming diamagnetism of the $\mathrm{Fe}^{\mathrm{II}}$ site. 


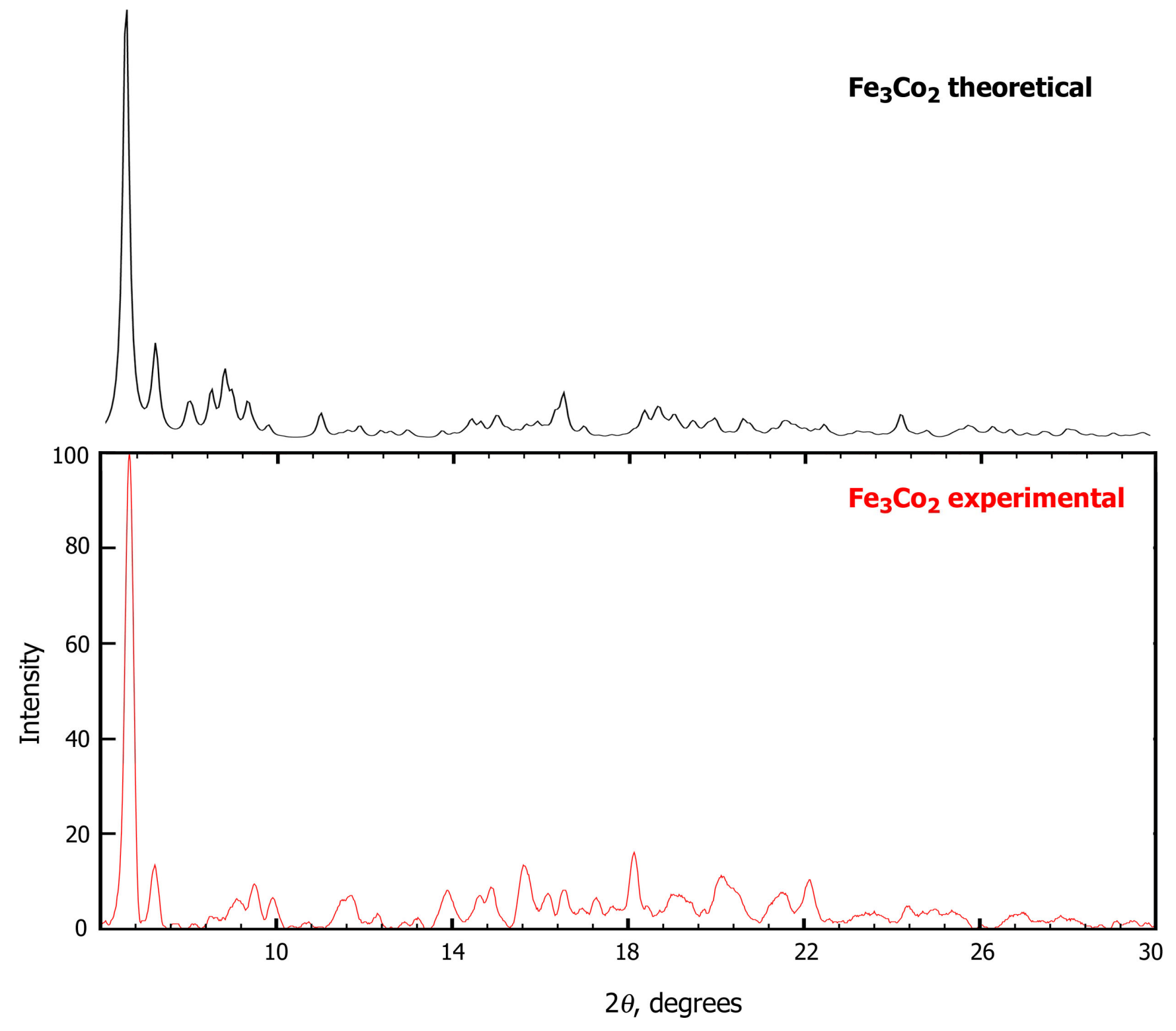

Figure S7. X-ray powder diffraction pattern for compound 4. 


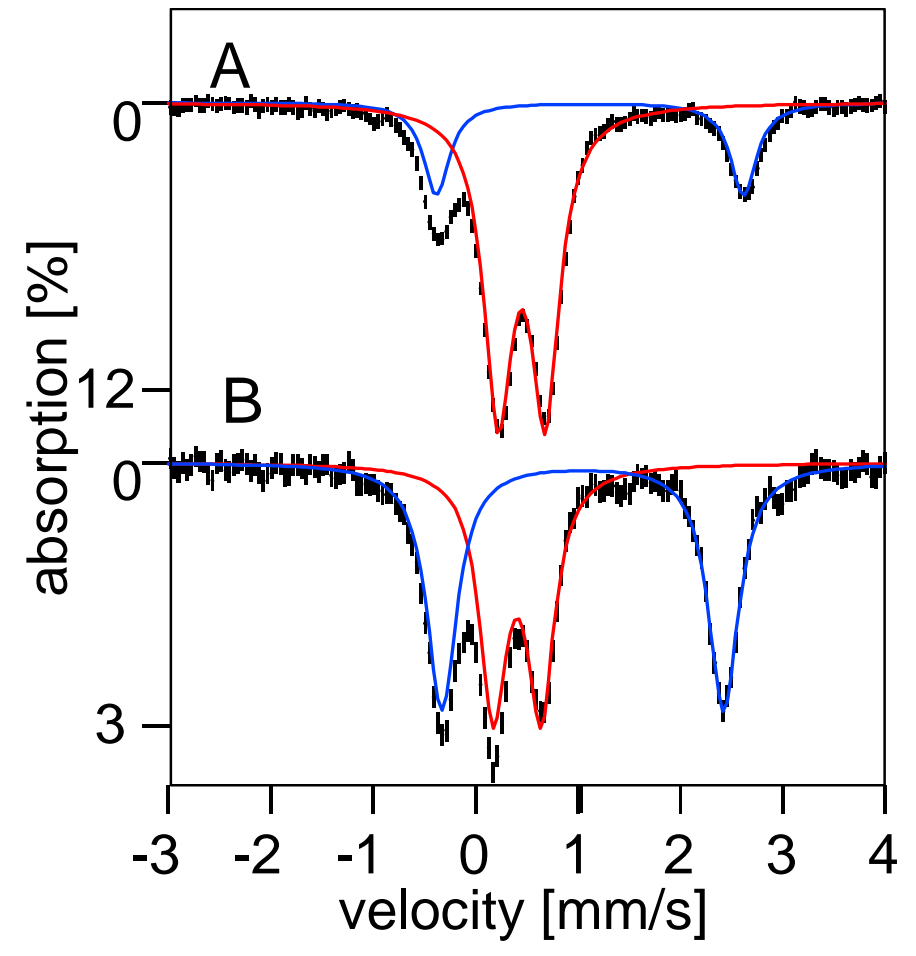

Figure S8. 0.05 -T Mössbauer spectra recorded at 4.2 (A), and 220 K (B) for acetonitrile-wet crystals of 4 . 


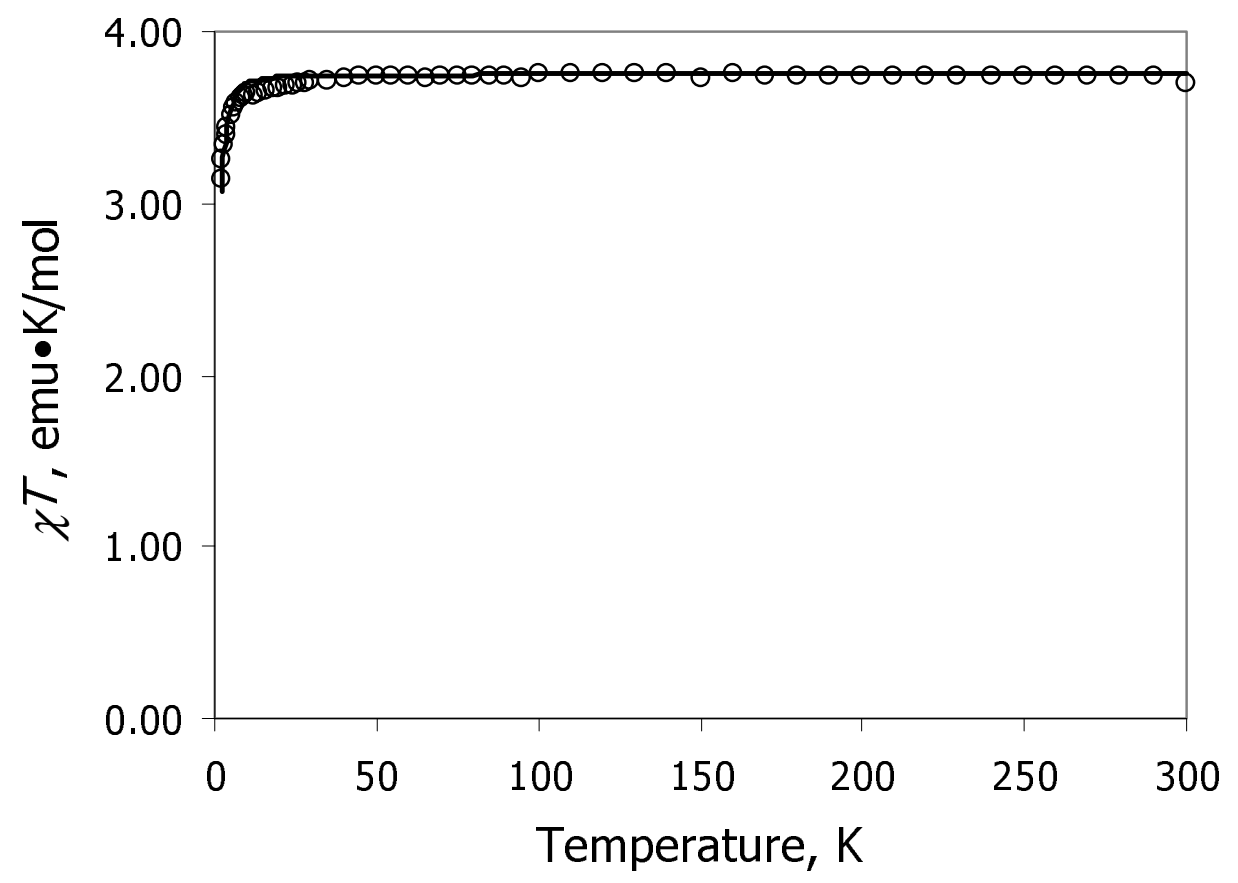

Figure S9. Temperature dependence of $\chi T$ for compound $1(0)$.

The solid line represents the best fit to the experimental data obtained assuming the existence of zero field splitting at $\mathrm{Cr}^{\mathrm{III}}$, i.e. $\chi T=\frac{3 N_{A} \mu_{\mathrm{B}}{ }^{2} g^{2}}{4 k} \cdot\left[1+\frac{2 \tanh (D / k T)}{3 D / k T}\right]$ with $g_{\mathrm{Cr} \|}=g_{\mathrm{Cr}} \perp=2.00$ and $\left|D_{\mathrm{Cr}}\right|=$ $2.4 \mathrm{~cm}^{-1}(R 2=0.9987) . R 2=1-\sqrt{\frac{\sum\left(\chi T_{\text {obs }}-\chi T_{\text {calc }}\right)^{2}}{(n-p) \times \sum\left(\chi T_{\text {obs }}\right)^{2}}}$, where $n$ is the number of experimental data points and $p$ is the number of refined parameters.

Comments: The expression for $\chi \mathrm{T}$ is valid for $\frac{\mu_{\mathrm{B}} H}{k T} \ll<$, a condition met for the experimental conditions (applied field of $0.1 \mathrm{~T}$ and temperature $\mathrm{T}>2 \mathrm{~K}$ ). This expression shows that (1) $\chi \mathrm{T}$ does not depend on the sign of the zero field splitting $\mathrm{D}$; and (2) $\chi \mathrm{T}$ increases with the increasing temperature for both positive and negative $\mathrm{D}$-values. These comments are also relevant in the analysis of the magnetic properties for complex 5 . 


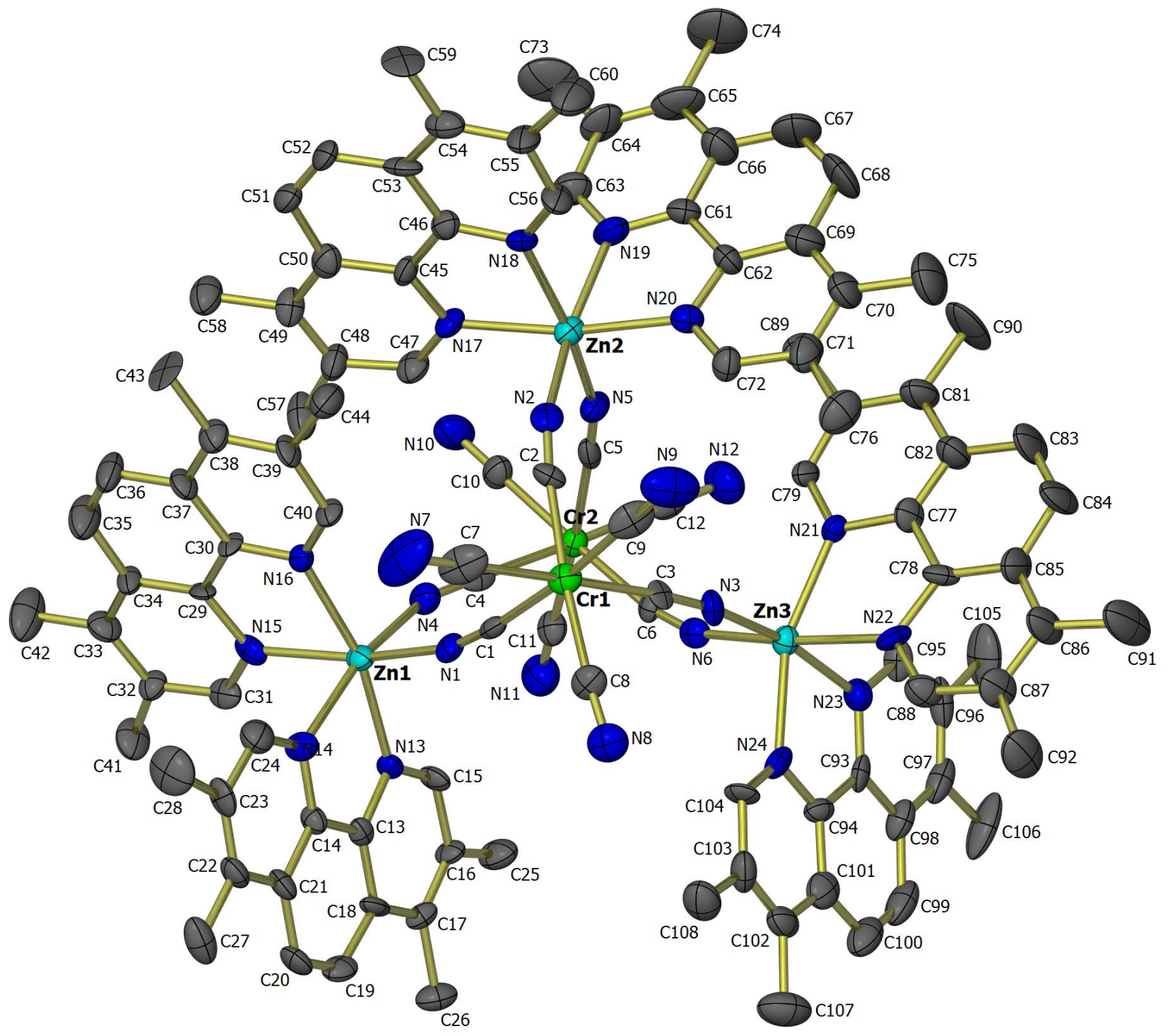

Figure S10. Thermal ellipsoid plot of 1 (50\% probability level; $\mathrm{H}$ atoms are omitted for clarity). 


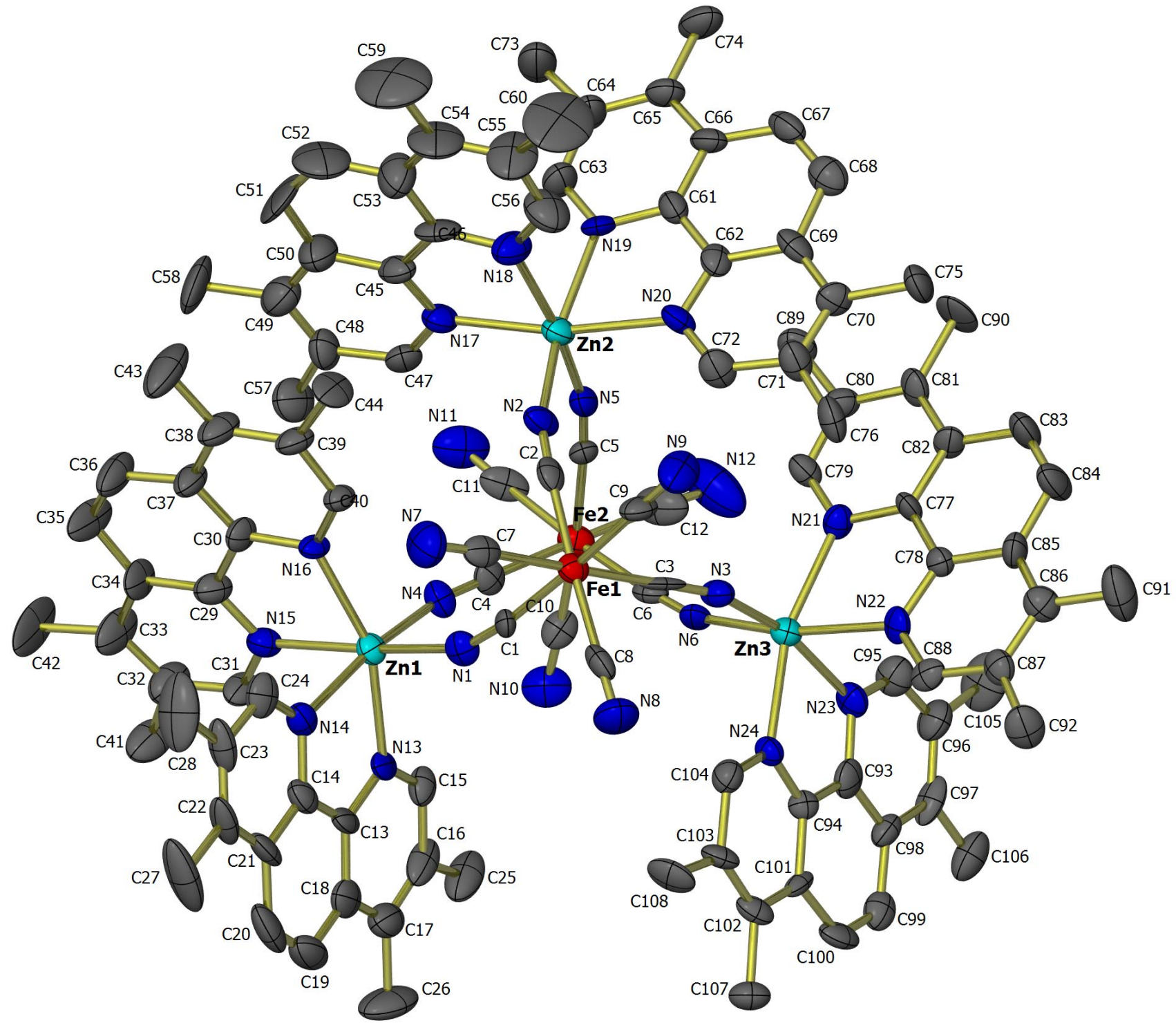

Figure S11. Thermal ellipsoid plot of 2 (50\% probability level; H atoms are omitted for clarity). 


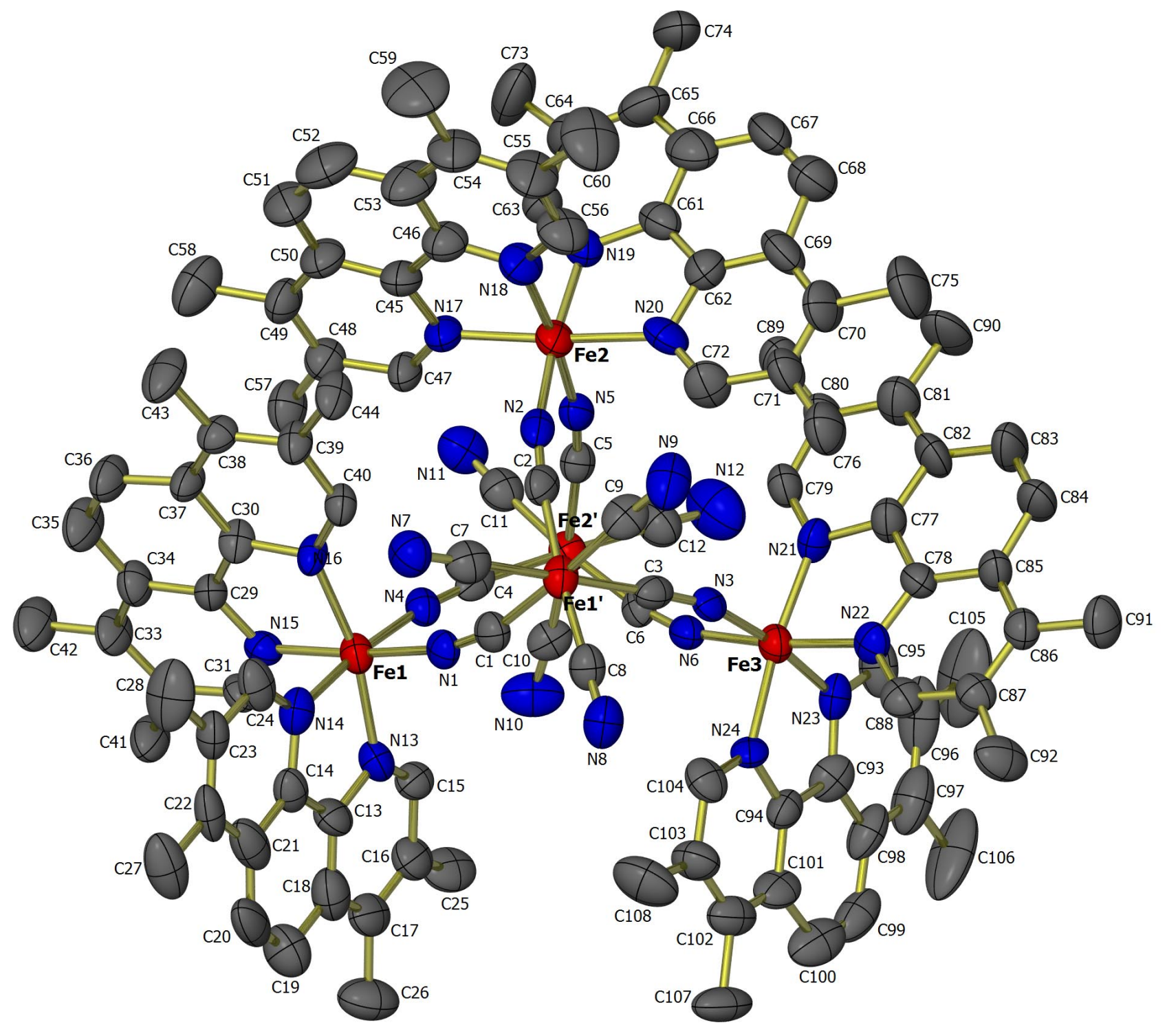

Figure S12. Thermal ellipsoid plot of 3 (50\% probability level; $\mathrm{H}$ atoms are omitted for clarity). 


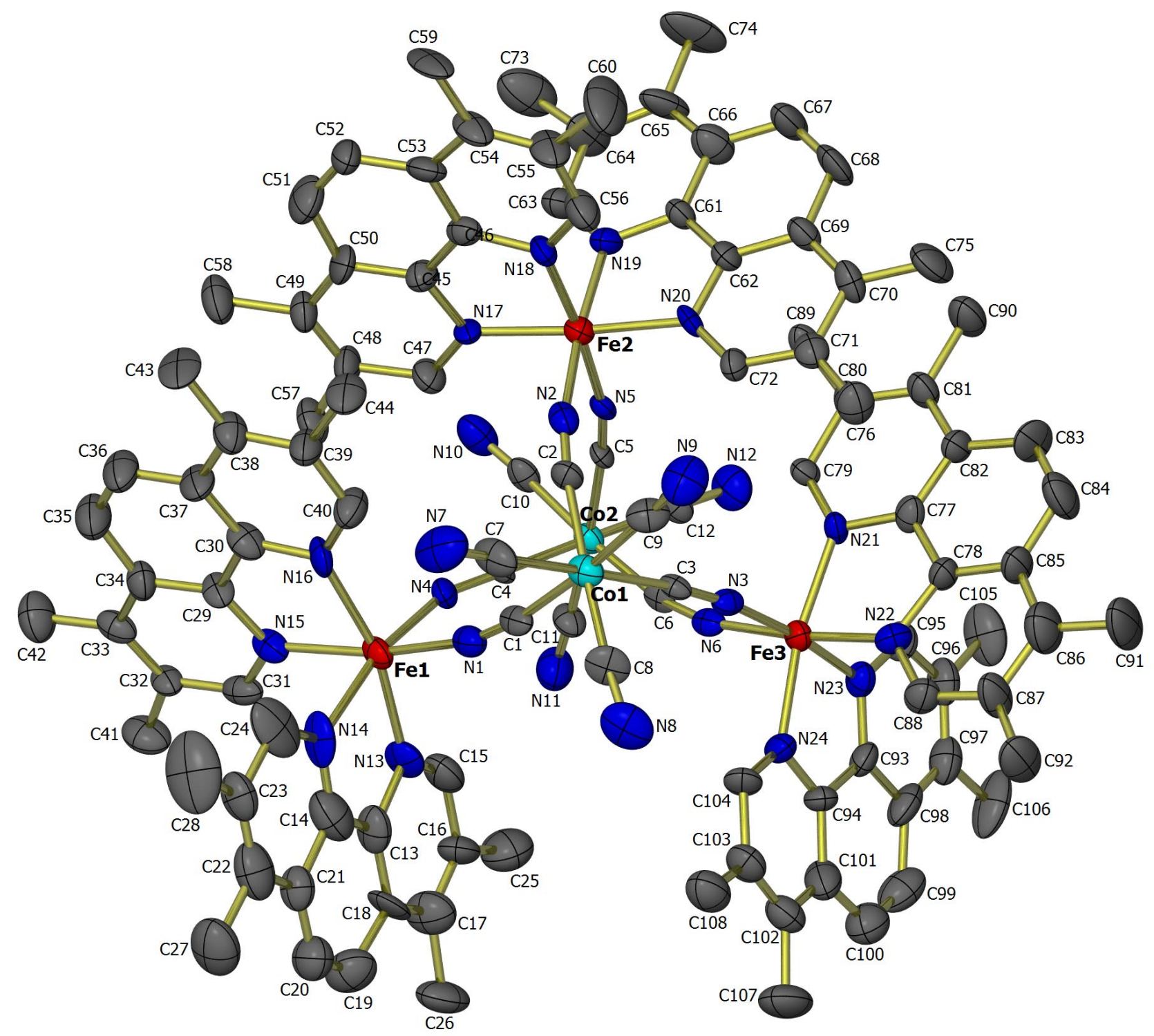

Figure S13. Thermal ellipsoid plot of 4 (the structure determined at $110 \mathrm{~K} ; 50 \%$ probability level; H atoms are omitted for clarity). 


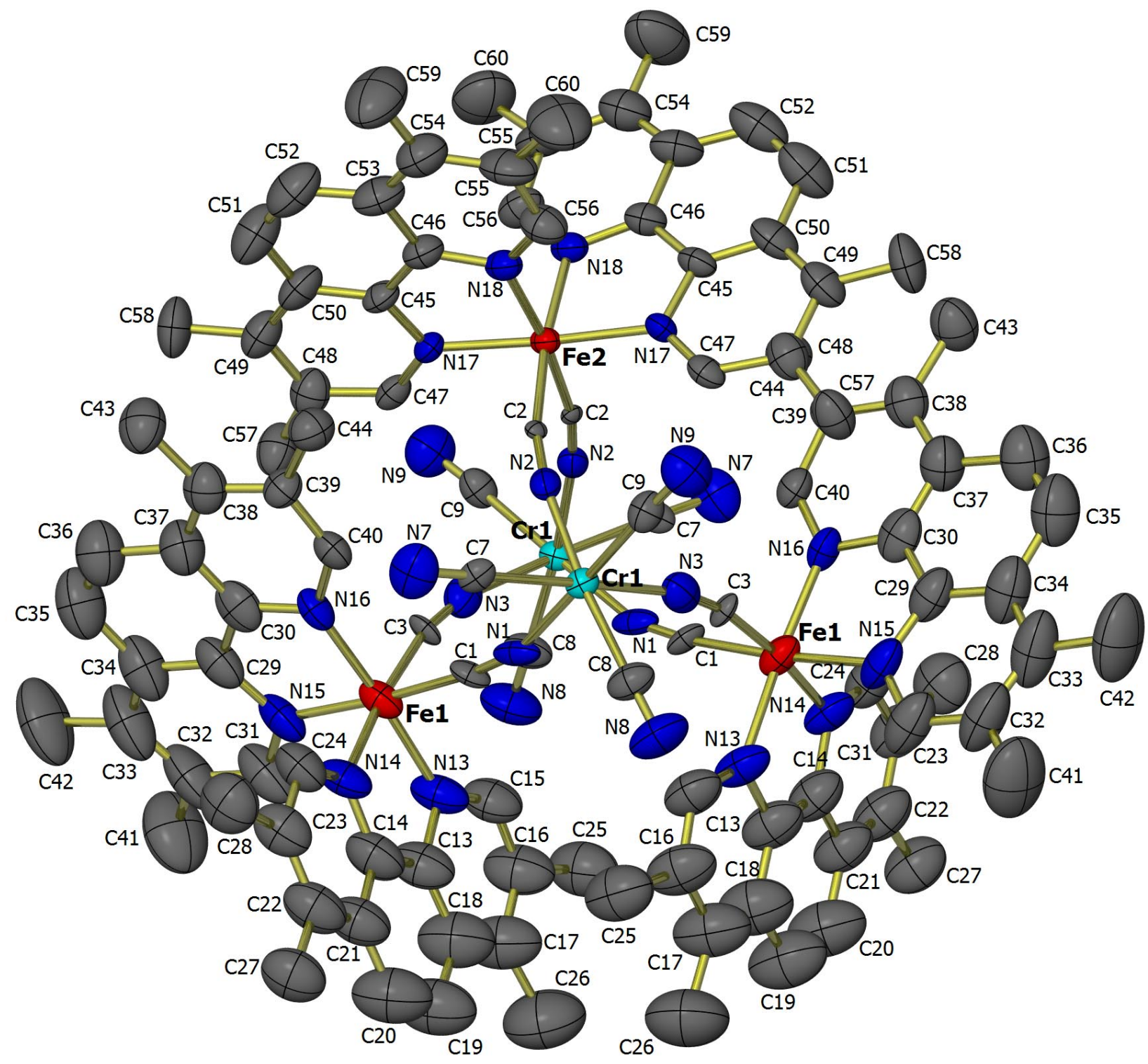

Figure S14. Thermal ellipsoid plot of 5 (50\% probability level; H atoms are omitted for clarity). 